\section{Intramolecular fractionation of hydrogen isotopes in silicate quenched melts}

\section{Le Losq ${ }^{1,2 *}$, B.O. Mysen ${ }^{1}$, G.D. Cody ${ }^{1}$}

\section{open 2 ACCES}

\section{Abstract}

doi: 10.7185/geochemlet.1609

The interplay between the chemical composition and the molecular structure of silicate melts was central to the evolution of the Earth's crust, mantle and core. This interplay also affects geochemical records such as the partitioning of isotopes between minerals, melts and fluids in the Earth's interior. For instance, large ${ }^{2} \mathrm{H} /{ }^{1} \mathrm{H}$ fractionations between silicate melts and aqueous fluids have been observed at high temperature and pressure. Such behaviour may be promoted by the occurrence of ${ }^{2} \mathrm{H} /{ }^{1} \mathrm{H}$ intramolecular fractionation within the molecular structure of silicate melts. New Raman spectroscopy and ${ }^{1} \mathrm{H}$ and ${ }^{2} \mathrm{H}$ Nucter Te Resonance (N S (a) with the melt silicate network.

Received 24 November 2015 | Accepted 21 January 2016 | Published 16 February 2016

\section{Introduction}

Silicate melts played a determining role in the segregation and evolution of the Earth's crust, mantle and core (e.g., Wood et al., 2006; Labrosse et al., 2007). Characterisation of their structure is central to understanding those processes. The silicate melt structure comprises network forming ions $\left(\mathrm{Si}^{4+}, \mathrm{Al}^{3+}, \mathrm{Fe}^{3+} \ldots\right)$ in interconnected oxygen polyhedra, forming a network that can be disrupted by network modifiers ions, e.g., $\mathrm{Mg}^{2+}, \mathrm{Ca}^{2+}, \mathrm{K}^{+}, \mathrm{Na}^{+}$. The latter may also act as charge compensators of the $\mathrm{O}^{2-}$ bonded to network forming trivalent cations. Additional complexity arises from large variations in $\mathrm{Si}-\mathrm{O}-\mathrm{Si} / \mathrm{Si}-\mathrm{O}-\mathrm{Al}$ bond angles and cationic coordination numbers, and non-random mixing and partitioning of the cations (Mysen and Richet, 2005; Greaves and Sen, 2007)

1. Geophysical Laboratory, Carnegie Institution of Washington, 5251 Broad Branch Road NW, 20015 Washington D.C., USA

Present address: Research School of Earth Sciences, The Australian National University, Building 142 Mills Road, ACT 2601 Canberra, Australia

Corresponding author (email: charles.lelosq@anu.edu.au)

From this structural complexity may arise peculiar effects on the partitioning of isotopes between silicate melts, minerals, and aqueous fluids. For example, the partitioning of ${ }^{15} \mathrm{~N} /{ }^{14} \mathrm{~N}$, of ${ }^{13} \mathrm{C} /{ }^{12} \mathrm{C}$, and of ${ }^{2} \mathrm{H} /{ }^{1} \mathrm{H}$ between sodium silicate melts and aqueous fluids depends on the melt structure (Mysen et al., 2009; Mysen and Fogel, 2010). The ${ }^{34} \mathrm{~S} /{ }^{32} \mathrm{~S}$ fractionation between aluminosilicate melts and metals also depends on the proportion of network formers $\mathrm{Al}^{3+}$ or $\mathrm{B}^{3+}$ in the melts (Labidi et al., 2016). Further, the behaviour of Fe isotopes in silicate melts is affected by the effects of melt composition on the Fe environment (Dauphas et al., 2014).

The ${ }^{2} \mathrm{H}$ and ${ }^{1} \mathrm{H}$ isotopes may be particularly strongly affected by intramolecular processes in silicate melts because of their large difference in mass. Results from ${ }^{1} \mathrm{H}$ and ${ }^{2} \mathrm{H}$ Rotor-synchronised Magic-Angle Spinning (MAS) Nuclear Magnetic Resonance (NMR) spectroscopy of hydrous sodium tetrasilicate and MORB-like glasses indicate that ${ }^{2} \mathrm{H}$ tends to populate environments with shorter $\mathrm{O}-\mathrm{O}$ distances compared to ${ }^{1} \mathrm{H}$ in quenched melts (Wang et al, 2015). Therefore, ${ }^{2} \mathrm{H}$ and ${ }^{1} \mathrm{H}$ seem to fractionate between the various molecular environments in silicate melts.

Such ${ }^{2} \mathrm{H} /{ }^{1} \mathrm{H}$ intramolecular fractionation may help understanding the large ${ }^{2} \mathrm{H} /{ }^{1} \mathrm{H}$ isotopic fractionation observed between silicate melts and aqueous fluids. Indeed, in situ Raman observations in diamond cells show that $\alpha_{\text {fluid-melt }}=$ $\left(\frac{{ }^{2} H}{{ }^{1} H}\right)_{\text {fluid }}\left(\frac{{ }^{2} H}{{ }^{1} H}\right)_{\text {melt }}$ may reach hundreds of \%o at temperatures and pressures as high as $700{ }^{\circ} \mathrm{C}$ and $1.5 \mathrm{GPa}$ (Mysen, 2013a,b; Dalou et al., 2015). Such values are higher than typical $\alpha_{\text {fluid-mineral }}$ in the tens of \%o level (Chacko et al., 2001). According to the results of Wang et al. (2015), the intramolecular fractionation of ${ }^{2} \mathrm{H}$ and ${ }^{1} \mathrm{H}$ in silicate melts results in differences between the mean $\mathrm{O}^{-1} \mathrm{H}$ and $\mathrm{O}_{-}{ }^{2} \mathrm{H}$ bond lengths. Therefore, it may enhance the differences of ${ }_{-}{ }^{1} \mathrm{H}$ and $\mathrm{O}_{-}{ }^{2} \mathrm{H}$ bond strengths between silicate melts and aqueous fluids, and, as a result, promote a strong fractionation of both isotopes between those substances (Schauble, 2004 and references therein).

To gain further understanding of such process, we performed Raman spectroscopy and ${ }^{1} \mathrm{H}$ and ${ }^{2} \mathrm{H}$ Rotor-synchronised MAS NMR observations of $\mathrm{Li}_{2} \mathrm{Si}_{4} \mathrm{O}_{9}$ $\mathrm{Na}_{2} \mathrm{Si}_{4} \mathrm{O}_{9}$ and $\mathrm{K}_{2} \mathrm{Si}_{4} \mathrm{O}_{9}$ melts quenched from high temperature and pressure, and containing ${ }^{1} \mathrm{H}_{2} \mathrm{O},{ }^{2} \mathrm{H}_{2} \mathrm{O}$, or a mixture of both (Table S-1). Experimental methods are described in Supplementary Information and all acquired NMR and Raman spectra are provided in Supplementary Figures S-1, S-2, S-3 and S-4.

\title{
Results
}

${ }^{1} \mathrm{H}$ and ${ }^{2} \mathrm{H}$ isotropic NMR spectra of the hydrous alkali quenched melts present three main peaks near 16, 5 and $1.8 \mathrm{ppm}$ in three frequency regions, HF, MF and LF (Fig. 1, Supplementary Information). The ${ }^{2} \mathrm{H}$ signal is systematically more intense in the HF region and less intense in the MF region relative to that 


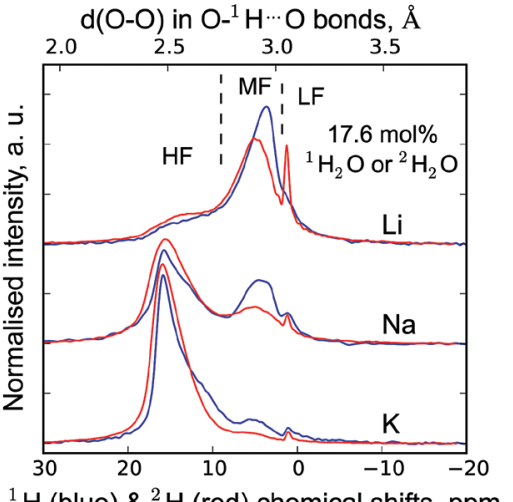

${ }^{1} \mathrm{H}$ (blue) \& ${ }^{2} \mathrm{H}$ (red) chemical shifts, ppm

Figure $1{ }^{1} \mathrm{H}$ and ${ }^{2} \mathrm{H}$ isotropic MAS NMR spectra of the alkali tetrasilicate glasses containing 17.6 $\mathrm{O}-\mathrm{H} \cdots \mathrm{O}$ bonds have been determined from the ${ }^{1} \mathrm{H}$ chemical shifts following Xue and Kanzaki (2009).

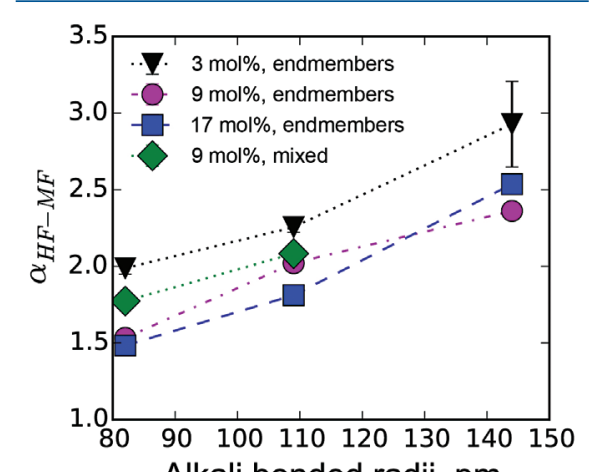
Alkali bonded radii, pm

Figure $2 \alpha_{\mathrm{HF}-\mathrm{MF}}\left(=\left({ }^{2} \mathrm{H} /{ }^{1} \mathrm{H}\right)_{\mathrm{HF}} /\left({ }^{2} \mathrm{H} /{ }^{1} \mathrm{H}\right)_{\mathrm{MF}}\right)$ intramolecular fractionation factors between the environments linked to the $\mathrm{HF}$ and MF regions in the ${ }^{1} \mathrm{H}$ and ${ }^{2} \mathrm{H}$ NMR spectra (Supplementary Information). Inverted triangles, circles and squares: determined from the NMR data of "endmembers" glasses containing pure ${ }^{1} \mathrm{H}_{2} \mathrm{O}$ and pure ${ }^{2} \mathrm{H}_{2} \mathrm{O}$; diamonds: determined from the NMR data of the glasses with mixed ${ }^{1} \mathrm{H}_{2} \mathrm{O}-{ }^{2} \mathrm{H}_{2} \mathrm{O}$ (1:1 ratio; no fractionation factor is provided at $144 \mathrm{pm}$ as the NMR data for K-bearing glass were too noisy to provide an accurate estimation). Alkali bonded radii are from Gibbs et al. (2014), assuming 6 fold coordinated alkalis.

of ${ }^{1} \mathrm{H}$ at any water content and glass composition (Fig. 1). The intensity in the LF region of the ${ }^{1} \mathrm{H}$ and ${ }^{2} \mathrm{H}$ NMR spectra also differs, but in a non systematic way such that it is difficult to ascribe those changes to an isotopic effect. Furthermore, the area of the LF peak constitutes a small $(<5 \%)$ fraction of the total integrated NMR intensity. For those reasons, we will not consider it further.

The differences in ${ }^{2} \mathrm{H}$ and ${ }^{1} \mathrm{H}$ isotropic NMR spectra indicate that ${ }^{2} \mathrm{H}$ and ${ }^{1} \mathrm{H}$ fractionate between different environments in the silicate melt structure, with ${ }^{2} \mathrm{H}$ preferentially populating environments with small $\mathrm{O}-\mathrm{O}$ distances (Fig. 1). This effect can be quantified by calculating the fractionation factor between the $\mathrm{HF}$ and MF spectral regions, $\alpha_{\text {HF-MF }}$ (Fig. 2). $\alpha_{\text {HF-MF }}$ depends primarily on the alkali ionic radius, as shown by a $\sim 65 \%$ variation between the $\mathrm{Li}$ and $\mathrm{K}$ glasses, and secondarily on the glass water content. The latter influence probably originates from the fact that increasing the water content increases the fraction of molecular water, which gives a weak signal in the MF portion of ${ }^{2} \mathrm{H}$ and ${ }^{1} \mathrm{H}$ NMR spectra.

The signals in the 850-1300 $\mathrm{cm}^{-1}$ portion of the Raman spectra of glasses with comparable composition and water content, but containing either pure ${ }^{1} \mathrm{H}_{2} \mathrm{O}$ or pure ${ }^{2} \mathrm{H}_{2} \mathrm{O}$, systematically differ from each other (Fig. 3). The intensity of the signal assigned to $\mathrm{Si}-\mathrm{O}$ stretching in $Q^{3}$ units $\left(1100 \mathrm{~cm}^{-1}\right)$ is enhanced by the presence of ${ }^{2} \mathrm{H}_{2} \mathrm{O}$, whereas that assigned to $\mathrm{Si}-\mathrm{O}$ stretching in $Q^{2}$ units $\left(\sim 950 \mathrm{~cm}^{-1}\right)$ is lowered (Supplementary Information for additional detail). This observation is confirmed by subtraction of the Raman spectra of the ${ }^{1} \mathrm{H}_{2} \mathrm{O}$-bearing glasses from those of the ${ }^{2} \mathrm{H}_{2} \mathrm{O}$-bearing glasses (Fig. 3b). The variations of the intensity near $1150-1200 \mathrm{~cm}^{-1}$, where the signal from $\mathrm{Si}-\mathrm{O}$ stretching in $Q^{4}$ units occurs, are negligible compared with those of the $\sim 950$ and $\sim 1100 \mathrm{~cm}^{-1}$ signals.

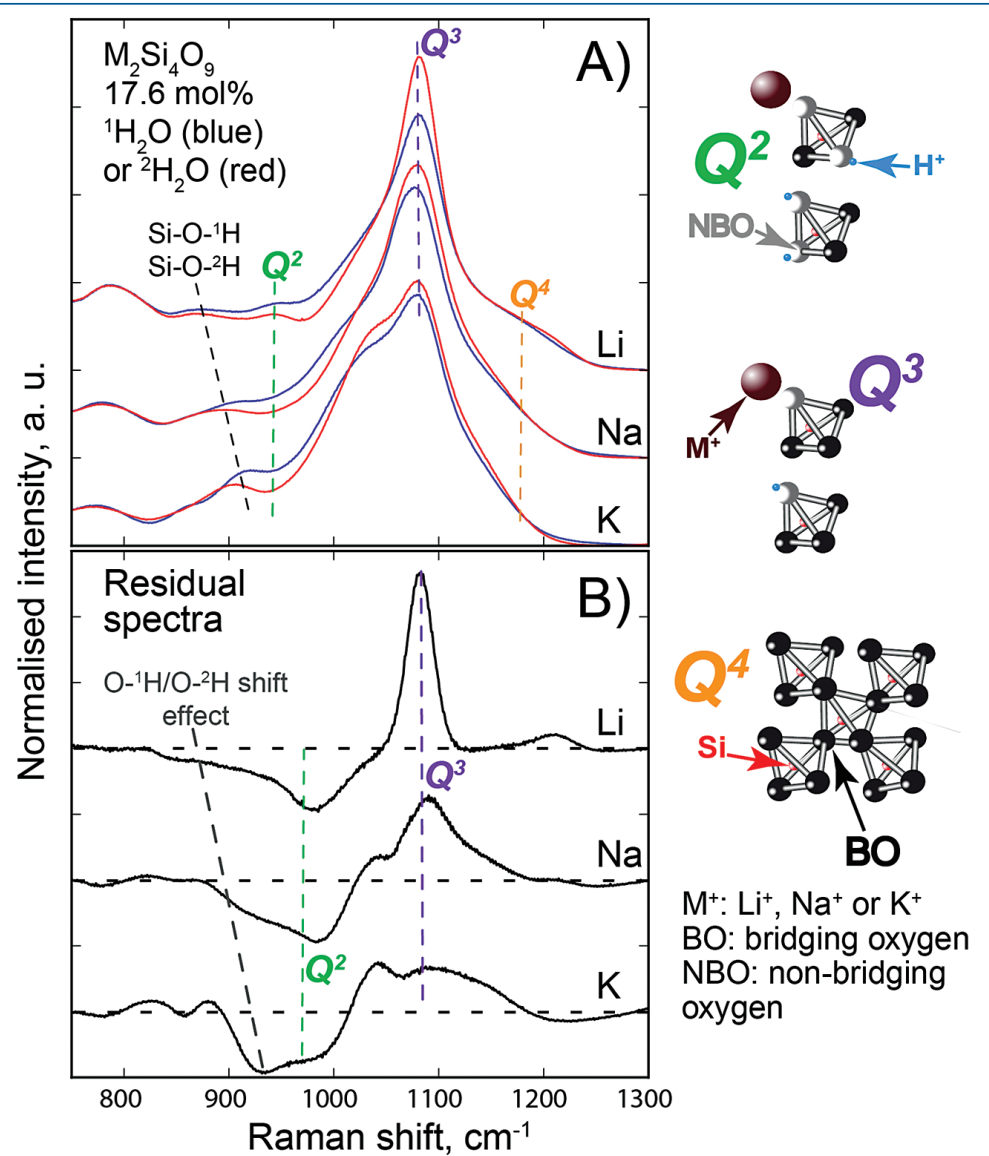

Figure 3 (a) $750-1300 \mathrm{~cm}^{-1}$ portion of Raman spectra of the alkali silicate glasses containing $17.6 \mathrm{~mol} \%$ of pure ${ }^{1} \mathrm{H}_{2} \mathrm{O}$ (blue lines) or ${ }^{2} \mathrm{H}_{2} \mathrm{O}$ (red lines). (b) Residual spectra from the subtraction of the Raman spectra of the ${ }^{1} \mathrm{H}_{2} \mathrm{O}$-bearing glasses from those of the ${ }^{2} \mathrm{H}_{2} \mathrm{O}$-bearing glasses. The crequency shift a the bridging oxygen atoms, that form the molecular disordered backbone of silicate melts. 


\section{Discussion}

The decrease of the $Q^{2}$ abundance and the increase of the $Q^{3}$ abundance by substitution of ${ }^{1} \mathrm{H}$ for ${ }^{2} \mathrm{H}$ seen in the Raman spectra of the glasses explain the variations of the ${ }^{1} \mathrm{H}$ and ${ }^{2} \mathrm{H}$ NMR signals. Indeed, from $\left\{{ }^{1} \mathrm{H}\right\}-{ }^{29} \mathrm{Si} \mathrm{HETCOR} \mathrm{NMR}$ data of $\mathrm{Na}_{2} \mathrm{Si}_{4} \mathrm{O}_{9}$ hydrous glasses (Robert et al., 2001), the ${ }^{1} \mathrm{H} 16$ ppm NMR signal is strongly correlated with the ${ }^{29} \mathrm{Si}$ NMR signal from $Q^{3}$ units, and is only weakly correlated with that of $Q^{2}$ units. An increase of $Q^{3}$ abundance with substitution of ${ }^{1} \mathrm{H}$ by ${ }^{2} \mathrm{H}$ in the glasses thus explains the higher ${ }^{2} \mathrm{H}$ NMR signal near $16 \mathrm{ppm}$ (Figs. 1, S-1, S-2). Therefore, we conclude that, compared to ${ }^{1} \mathrm{H},{ }^{2} \mathrm{H}$ preferentially bonds with non-bridging oxygens in $Q^{3}$ units relative to $Q^{2}$ units. From the variations in the Raman signal intensity, the differences range between 0.5 and $4 \%$.

This intramolecular fractionation of ${ }^{2} \mathrm{H}$ and ${ }^{1} \mathrm{H}$ between the $Q^{n}$ units explains the variations of $\alpha_{\mathrm{HF}-\mathrm{MF}}$ as a function of composition (Fig. 2). Indeed, with increasing alkali ionic radius, both the distribution of $Q^{n}$ species and the proton environment change (Le Losq et al., 2015). These factors affect the ${ }^{2} \mathrm{H} /{ }^{1} \mathrm{H}$ intramolecular fractionation. The latter probably occurs at high temperature in the molten state, far from the melt glass transition temperature, $\mathrm{Tg}$. This hypothesis is supported by the fact that the quench rate affects the $T g$ and the water speciation (e.g., Behrens and Yamashita, 2008), but has no effect on the ${ }^{2} \mathrm{H} /{ }^{1} \mathrm{H}$ intramolecular fractionation (Wang et al., 2015).

Wang et al. (2015) proposed that the intramolecular fractionation of ${ }^{1} \mathrm{H}$ and ${ }^{2} \mathrm{H}$ observed in the glasses arises from a molar volume isotope effect (e.g. Driesner et al., 1997), which may be analogous to that observed in the brucitewater system (Horita et al., 1999, 2002, 2010). Following Wang et al. (2015), ${ }^{2} \mathrm{H}$ would preferentially occupy environments in silicate melts with smaller $\mathrm{O}-\mathrm{O}$ distances, and hence volumes compared to ${ }^{1} \mathrm{H}$, explaining the ${ }^{2} \mathrm{H}$ and ${ }^{1} \mathrm{H}$ NMR data (Fig. 1). The present Raman data offer further understanding by showing the bonding preferences of ${ }^{2} \mathrm{H}$ and ${ }^{1} \mathrm{H}$ for different silicate units in the glasses. Such bonding preferences may result from different "effective" ionic radii of ${ }^{1} \mathrm{H}$ and ${ }^{2} \mathrm{H}$ in silicate melts, induced by their different quantum mechanical properties This is analogous to the alkali ionic radius effect on the $Q^{n}$ units distribution in silicate melts (e.g., Maekawa et al., 1991).

The equilibrium fractionation of isotopes between different substances is governed by the different strengths of the bonds that the isotopes form in the substances (Schauble, 2004 and references therein). In silicate melts at high temperature, water is mostly present as $\mathrm{OH}$ groups (e.g., Behrens and Yamashita 2008), with protons interacting with the $Q^{n}$ units. The present data indicate that, in such conditions, ${ }^{2} \mathrm{H}$ populates the environments characterised by short $\mathrm{O}-\mathrm{O}$ distances, and, hence long $\mathrm{O}-\mathrm{H}$ bonds, slightly more than does ${ }^{1} \mathrm{H}$ (Fig. 1, the shortening of $\mathrm{O}-\mathrm{O}$ bonds around protons enhances hydrogen bonding, pulling away the protons from the "primary" O, see Novak, 1974). As a result, the mean $\mathrm{O}-{ }^{2} \mathrm{H}$ bond strength will be less than the mean ${ }^{-1}{ }^{1} \mathrm{H}$ bond strength in the melt.
Such phenomena may affect the differences in $\mathrm{O}_{-}{ }^{2} \mathrm{H}$ bond strength between silicate melts and aqueous fluids. Therefore, these structural features can control the isotopic fractionation of ${ }^{2} \mathrm{H}$ and ${ }^{1} \mathrm{H}$ between the melts and the fluids. This theory might explain the large fractionation of ${ }^{2} \mathrm{H}$ and ${ }^{1} \mathrm{H}$ between those substances (Mysen, 2013a,b; Dalou et al., 2015)

The link between the chemical composition and the speciation of $Q^{n}$ units (e.g., Mysen and Richet, 2005) implies that the intramolecular fractionation of ${ }^{2} \mathrm{H}$ and ${ }^{1} \mathrm{H}$ depends on the melt composition (Fig. 2). This may result in compositionally-dependent $\alpha_{\text {fluid-melt }}, \alpha_{\text {vapour-melt }}$ and $\alpha_{\text {mineral-melt }}$ fractionation factors, correlated with magmatic differentiation. Moreover, the intramolecular fractionation effect affects the fraction of water that interacts structurally with the silicate network, i.e. the so-called hydroxyl groups. Therefore, the influence of this effect on the $\alpha_{\text {fluid-melt }}, \alpha_{\text {vapour-melt }}$ and $\alpha_{\text {mineral-melt }}$ fractionation factors can also depend on water speciation. This may not be crucial at high temperatures where most of the water resides as $\mathrm{OH}$ groups in the melt, but it might play a determining role at temperatures corresponding to superficial volcanism, where magma degassing occurs. Such an idea agrees with an $\alpha_{\text {vapour-melt }}$ that depends on water speciation (De Hoog et al., 2009 and references therein).

The discussion above emphasises the centrally important principles that affect ${ }^{2} \mathrm{H} /{ }^{1} \mathrm{H}$ fractionation with implications for a range of geochemical problems. However, quantitative characterisation of how intramolecular fractionation of ${ }^{2} \mathrm{H}$ and ${ }^{1} \mathrm{H}$ in silicate melts governs hydrogen isotope fractionation processes in nature remain to be assessed. This fractionation of ${ }^{2} \mathrm{H}$ and ${ }^{1} \mathrm{H}$ between the $Q^{n}$ units of silicate melts likely reflects different extents of steric hindrance. This is analogous to the different distribution of alkali metals among structural units, for example (Maekawa et al., 1991). Such structural complexity, in turn, may affect other isotopic systems for which the isotopes interact with the $Q^{n}$ units as reported, for example, for ${ }^{15} \mathrm{~N} /{ }^{14} \mathrm{~N}$ (Mysen and Fogel, 2010), for ${ }^{13} \mathrm{C} /{ }^{12} \mathrm{C}$ (Mysen et al., 2009), or for the isotopes of $S$ (Labidi et al., 2016). Therefore, it might have played an important influence on the geochemical isotopic record used to reconstruct the history of the Earth and other silicate planets.

\section{Acknowledgements}

All NMR experiments were performed at the W.M. Keck Solid State NMR Facility at the Geophysical Laboratory, supported in part by the W.M. Keck Foundation. This research was supported in part by NSF grants EAR 121754 and EAR12504491, NASA Astrobiology and by the Carnegie Institution of Washington. The authors thank Jabrane Labidi and Anat Shahar (GL-CIW) for discussions on the present subject and their comments and corrections on the present manuscript, and Dionysis Foustoukos (GL-CIW) for helpful discussions and comments.

Editor: Bruce Watson 


\section{Additional Information}

Supplementary Information accompanies this letter at www.geochemicalperspectivesletters.org/article1609

Reprints and permission information is available online at http://www. geochemicalperspectivesletters.org/copyright-and-permissions

Cite this letter as: Le Losq, C., Mysen, B.O., Cody, G.D. (2016) Intramolecular fractionation of hydrogen isotopes in silicate quenched melts. Geochem. Persp. Let. 2, 87-94.

\section{References}

BEHRENS, H., YAMASHITA, S. (2008) Water speciation in hydrous sodium tetrasilicate and hexasilicate melts: Constraint from high temperature NIR spectroscopy. Chemical Geology 256, 306-315.

CHACKO, T., COLE, D.R., HoRITA, J. (2001) Equilibrium oxygen, hydrogen and carbon isotope fractionation factors applicable to geologic systems. Reviews in mineralogy and geochemistry 43, 1-81.

Dalou, C., Le Lose, C., Mysen, B.O. (2015) In situ study of the fractionation of hydrogen isotopes between aluminosilicate melts and coexisting aqueous fluids at high pressure and high temper158-166.

Dauphas, N., Roskosz, M., Alp, E.E., Neuville, D.R., Hu, M.Y., Sio, C.K., Cordier, C. (2014) Magma redox and structural controls on iron isotope variations in Earth's mantle and crust. Earth and Planetary Science Letters 398, 127-140 De HoOG, J.C., TAYLOR, B.E., VAN BERGEN, M.J. (2009) Hydrogen-isotope systematics in degas-
sing basaltic magma and application to Indonesian arc basalts. Chemical Geology 266, 256-266

DRIESNER, T. (1997) The effect of pressure on deuterium-hydrogen fractionation in high-temperature water. Science 277, 791-794.

GIBBS, G.V., Ross, N.L., Cox, D.F., Rosso, K.M. (2014) Insights into the crystal chemistry of Earth materials rendered by electron density distributions: Pauling's rules revisited. American Mineralogist 99, 1071-1084.

GREAVES, G.N., SEN, S. (2007) Inorganic glasses, glass-forming liquids and amorphizing solids. Advances in Physics 56, 1-166.

Horita, I., Driesner, T., Cole, D.R. (1999) Pressure effect on hydrogen isotope fractionation between brucite and water at elevated temperatures. Science 286, 1545-1547.

Horita, J., Cole, D.R., Polyakov, V.B., DriesneR, T. (2002) Experimental and theoretical study of pressure effects on hydrogen isotope fractionation in the system brucite-water at elevated temperatures. Geochimica et Cosmochimica Acta 66, 3769-3788.

Horita, J., Dos Santos, A.M., Tulk, C.A., Chakoumakos, B.C., Polyakov, V.B. (2010) Highpressure neutron diff
Minerals 37, 741-749.

Labidi, J., Shahar, A Le Lose C., Hillgren, VJ, Mysen, B.O., Farouhar, J. (2016) Experimentally determined sulfur isotope fractionation between metal and silicate and implications for planetary differentiation. Geochimica et Cosmochimica Acta 175, 181-194.

Labrosse, S., Hernlund, J.W., Coltice, N. (2007) A crystallizing dense magma ocean at the base of the Earth's mantle. Nature 450, 866-869.
Le LosQ, C., Mysen, B.O., Cody, G.D. (2015) Water and magmas: insights about the water solution mechanisms in alkali silicate melts from infrared, Raman, and ${ }^{29} \mathrm{Si}$ solid-state NMR spectroscopies. Progress in Earth and Planetary Sciences 2, 22, doi: 10.1186/s40645-015-0052-7.

Maekawa, H., MaeKawa, T., KaWAmura, K., YoKOHama, T. (1991) The structural groups of alkali silicate glasses determined from ${ }^{29} \mathrm{Si}$ MAS-NMR. Journal of Non-Crystalline Solids 127, 53-64.

MYSEN, B. (2013a) Hydrogen isotope fractionation between coexisting hydrous melt and silicatesaturated aqueous fluid: An experimental study in situ at high pressure and temperature. American Mineralogist 98, 376-386.

MYSEN, B. (2013b) Effects of fluid and melt density and structure on high-pressure and high-temperature experimental studies of hydrogen isotope partitioning between coexisting melt and aqueous fluid. American Mineralogist 98, 1754-1764

MYSEn, B., RICHET, P. (2005) Silicate glasses and melts: properties and structure. Vol. 10, Elsevier, Amsterdam, The Netherlands.

MYsen, B.O., FogeL, M.L. (2010) Nitrogen and hydrogen isotope compositions and solubility in silicate melts in equilibrium with reduced $(\mathrm{N}+\mathrm{H})$-bearing fluids at high pressure and temperature: effects of melt structure. American Mineralogist 95, 987-999.

MYsen, B.O., Fogel, M.L., MorrilL, P.L., CODY, G.D. (2009) Solution behavior of reduced C O $\mathrm{H}$ volatiles in silicate melts at high pressure and temperature. Geochimica et Cosmochimica Acta $73,1696-1710$.

NovAK, A. (1974) Hydrogen bonding in solids correlation of spectroscopic and crystallographic data. In: Large Molecules. Springer Berlin Heidelberg, 177-216.

Robert, E., Whittington, A., FAYon, F., Pichavant, M., Massiot, D. (2001) Structural characterization of water-bearing silicate and aluminosilicate glasses by high-resolution solid-state NMR. Chemical Geology 174, 291-305.

SCHAUbLE, E.A. (2004) Applying stable isotope fractionation theory to new systems. Reviews in Mineralogy and Geochemistry 55, 65-111.

WANG, Y., CODY, S.X., Foustoukos, D., Mysen, B.O., CODY, G.D. (2015) Very large differences in intramolecular D-H partitioning in hydrated silicate melts synthesized at upper mantle pressures and temperatures. American Mineralogist 100, 1182-1189.

Wood, B.J., WALTER, M.J., WADE, J. (2006) Accretion of the Earth and segregation of its core. Nature $441,825-833$.

XUE, X., KanZaKI, M. (2009) Proton distributions and hydrogen bonding in crystalline and glassy hydrous silicates and related inorganic materials: insights from high-resolution solid-state Nuclear Magnetic Resonance spectroscopy. Journal of the American Ceramic Society 92, 2803-2830. 